\title{
HUBUNGAN GAYA HIDUP DENGAN HIPERTENSI GURU SEKOLAH MENENGAH YANG MENGALAMI GULA DARAH PUASA TERGANGGU DI MAKASSAR
}

\section{RELATIONSHIP BETWEEN LIFESTYLE AND HYPERTENSION IN SECONDARY SCHOOL TEACHERS EXPERIENCING IMPAIRED FASTING GLUCOSE IN MAKASSAR}

\author{
St. Mutiatu Rahmah ${ }^{1}$, Nurhaedar Jafar ${ }^{2}$, Syamsiar S. Russeng ${ }^{3}$ \\ ${ }^{1}$ Program Gizi Ilmu Kesehatan Masyarakat Universitas Hasanuddin \\ ${ }^{2}$ Bagian Gizi, Fakultas Kesehatan Masyarakat, Universitas Hasanuddin \\ ${ }^{3}$ Bagian Kesehatan dan Keselamatan Kerja, Fakultas Pertanian Universitas Hasanuddin
}

\begin{abstract}
*AlamatKorespondensi: St. Mutiatu Rahmah, FakultasKesehatan Masyarakat UniversitasHasanuddin , Makassar, 90154, Hp: 085242400069, Email:mutiarahmah21@ymail.com
\end{abstract}

\begin{abstract}
ABSTRAK
Gaya hidup yang kurang sehat menjadi salah satu penyebab timbulnya penyakit degeneratif berupa diabetes mellitus dan hipertensi. Penelitian bertujuan mengetahui hubungan gaya hidup (pola konsumsi, perilaku merokok, tingkat stres, dan aktivitas fisik) dengan hipertensi guru sekolah menengah yang mengalami gula darah puasa terganggu di Makassar. Jenis penelitian ini adalah observasional dengan rancangan crosssectional. Sampel penelitian adalah guru SMPN dan SMAN di 12 sekolah yang mengalami gula darah puasa terganggu $(\geq 100 \mathrm{mg} / \mathrm{dl})$ ditetapkan melalui pemeriksaan kimia darah $(\mathrm{n}=55)$. Data diperoleh dari pemeriksaan gula darah puasa, tekanan darah, pola konsumsi, perilaku merokok, tingkat stres, dan aktivitas fisik. Pemeriksaan gula darah puasa dan pengukuran tekanan darah dengan sphygmomanometer dilakukan langsung oleh petugas prodia. Pola konsumsi dikumpulkan melalui recall 1x24 jam yang dinilai dengan Healthy Eating Indeks (HEI-2010), perilaku merokok diukur menggunakan kuesioner, tingkat stres diukur menggunakan kuesioner DASS 21, dan aktivitas fisik diukur menggunakan kuesioner WHO 2001 yang dinyatakan dengan nilai PAL (Physical Activity Level). Dalam penelitian ini menunjukkan sebagian besar sampel berjenis kelamin perempuan $(81,8 \%)$, berumur $\geq 50$ tahun $(72,7 \%)$, tingkat pendidikan sarjana (94,5\%), memiliki riwayat penyakit keluarga DM (74,5\%), dan mengalami obesitas sentral $(69,1 \%)$. Hasil analisis bivariat menunjukkan bahwa ada hubungan yang signifikan antara pola konsumsi (HEI 2010) dengan hipertensi $(\mathrm{p}=0,049)$. Akan tetapi tidak terdapat hubungan yang signifikan antara perilaku merokok dengan hipertensi $(\mathrm{p}=0,327)$, tingkat stress dengan hipertensi $(\mathrm{p}=0,178)$, dan aktivitas fisik dengan hipertensi $(\mathrm{p}=0,335)$. Disimpulkan bahwa pola konsumsi yang kurang memiliki hubungan dengan hipertensi.
\end{abstract}

Kata Kunci: Glukosa Darah Puasa, Gaya Hidup, Hipertensi

\begin{abstract}
Unhealthy lifestyles become one cause of degenerative diseases such as diabetes mellitus and hypertension. The study aimed to know the relationship between lifestyle (consumption pattern, smoking behavior, stress level, and physical activity) and hypertension in high school teachers who exparienced impaired fasting glucose in Makassar. The type of this study was observational with cross sectional design. The samples of the study were SMPN and SMAN teachers in 12 schools who had disturbed fasting blood glucose (100mg/dl) determined by blood chemistry examination $(n=55)$. Data were collected from fasting blood sugar, blood pressure, food consumption patterns, smoking behavior, stress levels, and physical activity. Fasting blood glucose and blood pressure measurements with sphygmomanometer were performed directly by the prodia officer. Food consumption patterns were collected through a 1x24-hour recall assessed by the Healthy Eating Index (HEI2010), smoking behavior was measured using a questionnaire, the stress level was measured using a DASS 21 questionnaire, and physical activity was measured using a 2001 WHO questionnaire expressed by PAL value (Physical Activity Level ). In this study, most of the samples were female (81.8\%), aged $\geq 50$ years $(72.7 \%)$, undergraduate education (94.5\%), history of DM family disease (74.5\%), and central obesity (69.1\%). The result of bivariate analysis shows that there is a significant correlation between consumption pattern (HEI 2010) with hypertension $(p=0,049)$. However, there was no significant correlation between smoking behavior with hypertension $(p=0,327)$, stress level with hypertension $(p=0,178)$, and physical activity with hypertension $(p$ = 0,335). It was concluded that food consumption patterns were less association to hypertension.
\end{abstract}

Keywords: Blood Glucose Fasting, Lifestyle, Hypertension 


\section{PENDAHULUAN}

Masalah kesehatan saat ini bukan hanya disebabkan oleh penyakit menular, namun kini muncul penyakit tidak menular. Gaya hidup yang kurang sehat menjadi salah satu penyebab timbulnya penyakit tidak menular seperti diabetes melitus, hipertensi, jantung, dan stroke. Pemicu dari penyakit tersebut diawali dengan gangguan metabolisme dalam tubuh biasa disebut dengan sindrom metabolik. Sindrom metabolik (SM) ditandai dengan 5 parameter utama yaitu kadar gula darah, obesitas sentral, tekanan darah, kadar tringliserida darah, dan kadar High Density Lipoprotein (HDL). Seseorang dikatakan mengalami sindrom metabolik apabila seseorang memiliki $\geq 3$ dari kriteria yang ada. Gula darah puasa terganggu adalah salah satu gejala klinis dalam sindrom metabolik. Diagnosis gula darah terganggu atau prediabetes yaitu ketika gula darah puasa $100-125 \mathrm{mg} / \mathrm{dL}$, sedangkan diabetes ketika gula darah $\geq 126$ mg/dL (Perkeni, 2015).

WHO memproyeksikan bahwa diabetes akan menjadi penyebab utama 7 kematian di tahun 2030 (WHO, 2016). Pada tahun 2015 China merupakan Negara yang tertinggi angka kejadian diabetes yaitu 109,6 juta kemudian India sekitar 69,2 juta dan Amerika serikat 29,3 juta. Untuk diabetes di Asia Tenggara adalah Malaysia 16,6\%, Singapura 12,8\%, Thailand $8 \%$, dan Indonesia 6,2\% (IDF, 2015). Berdasarkan data riskesdas 2013 dilihat kejadian diabetes mellitus di Indonesia mengalami peningkatan yaitu tahun 2007 sebesar 1,1\% menjadi 2,1\%. Kenaikan prevalensi diabetes mellitus di Sulawesi Selatan yaitu 0,8\% menjadi 3,4\% (Kemenkes, 2013). Prevalensi diabetes yang didiagnosis dokter tertinggi terdapat di Kabupaten Pinrang (2,8\%), Kota Makassar (2,5\%), Kabupaten Toraja Utara (2,3\%) dan Kota Palopo (2,1\%) (Dinas Kesehatan Provinsi Sulawesi Selatan, 2015).

Kondisi yang biasa berdampingan dengan diabetes mellitus adalah hipertensi, yang dapat memperparah keadaan orang yang menderita diabetes mellitus. Terbukti bahwa hipertensi dapat menyebabkan peningkatan risiko penyakit kardiovaskular empat kali lipat pada orang yang mengalami Diabetes Melitus (ESC Guidelines, 2013). Menurut The Eighth Report of the Joint National Committee on detection, education, and treatment of high blood pressure (JNC VII), hipertensi merupakan suatu keadaan dimana tekanan darah sistolik $\geq 140 \mathrm{mmHg}$ dan tekanan darah diastolik $\geq 90 \mathrm{mmHg}$. Hipertensi disebut sebagai "The Sillent Killer Disease", karena gejalanya tidak tampak dan sering menyebabkan berbagai penyakit seperti jantung, stroke yang berujung pada kematian (NHLBI, 2004). Pada tahun 2025 memperkirakan 1 milyar penduduk dunia menderita penyakit hipertensi. Prevalensi hipertensi tertinggi adalah di daerah Afrika sebesar $46 \%$ pada orang dewasa usia 25 tahun. Sedangkan prevalensi terendah adalah di Amerika sekitar 35\% orang dewasa. Di Asia Tenggara prevalensi hipertensi sekitar $36,1 \%$ yang berada pada urutan keenam dari seluruh wilayah regional WHO (WHO, 2013). Di Indonesia, prevalensi hipertensi berdasarkan wawancara (pernah didiagnosis dan minum obat hipertensi) yaitu dari 7,6\% tahun 2007 meningkat menjadi $9,5 \%$ pada tahun 2013 , sedangkan berdasarkan hasil pengukuran sebesar 25,8\% (Kemenkes, 2013). Prevalensi hipertensi di Sulawesi Selatan yang didapat melalui pengukuran pada umur $\geq 18$ tahun sebesar 28,1\% dan di Makassar (28,8\%) (Dinas Kesehatan Provinsi Sulawesi Selatan, 2015). Tingginya angka kejadian hipertensi di Makassar dibandingkan dengan angka kejadian nasional, membuat hal ini harus diperhatikan dan menjadi fokus utama untuk melakukan upaya dalam mencegahdan mengendalikan penyakit lainnya yang akan timbul.

Terjadinya hipertensi sangat banyak dipengaruhi oleh beberapa faktor gaya hidup seperti kurangnya aktivitas fisik dan obesitas, kebiasaan merokok, keadaan stres, riwayat keluarga, dan pola 
konsumsi makanan tinggi lemak hewani, kurang serat, tinggi natrium, dan rendah kalium (Lipoeto, 2002). Sebuah penelitian cross sectional di Provinsi Jiangsu Cina menunjukkan bahwa konsumsi garam yang tinggi berhubungan denganhipertensi dengan nilai $\mathrm{p}=0.001$ (Qin Yu, dkk, 2014). Begitupun dengan kebiasaan merokok sebatang setiap hari meningkatkan tekanan darah sistolik 10-25 mmHg serta menambah detak jantung 5-20 kali/menit (Sitorus, 2005). Penelitian pada kelompok usia 20 sampai 40 tahun di Mumbai bahwa terdapat $22,9 \%$ yang mengalami stres berat dan $16,2 \%$ diantaranya memiliki tekanan darah>140/90 mm Hghipertensi (Tadvi, 2016). Selain itu aktivitas yang rendah pula akan menurunkan elastisitas sistem jantung dan pembuluh darah (WHO, 2013).

Beberapa hasil penelitian tersebut yang melatarbelakangi penulis dalam memperoleh informasi terkait gaya hidup guru dengan kejadian hipertensi di lingkungan sekolah. Upaya ini bertujuan untuk pengendalian masalah kesehatan melalui pendidikan. Guru sebagai pengajar dan role model yang dapat memberikan contoh kepada peserta didik dalam pencegahan penyakit dan peningkatan kesehatan.

\section{BAHAN DAN METODE}

\section{Lokasi dan Rancangan Penelitian}

Penelitianini dilakukan di 12

Sekolah Menengah yang berada pada 3 Kecamatan di Kota Makassar yaitu Kecamatan Biringkanaya, Kecamatan Manggala, dan Kecamatan Tamalanrea. Sekolah tersebut meliputi SMPN 25, SMPN 9, SMPN 8, SMPN 19, SMPN 12, SMPN 30, SMAN 12, SMAN 7, SMAN 18, SMAN 10, SMAN 21, dan SMAN 6. Penelitian dilaksanakan pada bulan MeiAgustus 2017.Jenis Penelitian ini adalah Tabel 1 menunjukkan bahwa berdasarkan jenis kelamin persentase responden yang terbanyak adalah perempuan sebesar $81,8 \%$ dibandingkan dengan laki-laki yaitu 18,2\%. Berdasarkan observasional dengan rancangan cross sectional.

\section{Populasi dan Sampel}

Populasi dalam penelitian ini adalah seluruh guru di 12 Sekolah Menengah (SMPN dan SMAN) Kota Makassar yang berjumlah 595 guru. Tiga Kecamatan tersebut dipilih berdasarkan jumlah guru terbanyak yaitu Kecamatan Biringkanaya, Kecamatan Manggala, dan Kecamatan Tamalanrea.Sedangkan sampel penelitian ini adalah guru-guru yang melakukan pemeriksaan kimia darah dan terbukti mengalami gula darah puasa terangguatau memiliki kadar glukosa darah puasa $\geq 100 \mathrm{mg} /$ dl. Teknik pemilihan responden dengan metode Purposive Sampling, dan jumlah responden dalam penelitian ini sebanyak 55 orang.

\section{Metode Pengumpulan Data}

Metode pengambilan data dilakukan dengan pemeriksaan gula darah puasa dan tekanan darah oleh petugas laboratorium prodia. Selain itu dengan wawancara langsung yang mencakup karakteristik responden, pola konsumsi, perilaku merokok, tingkat stres, dan aktivitas fisik.

\section{Analisis Data}

Data yang terkumpul diolah dan dianalisis menggunakan program SPSS 21. Analisis data dengan univariat disajikan dalam bentuk tabel distribusi frekuensi, grafik, atau narasi dari tiap variable disertakan pembahasan dengan membandingkan teori-teori yang relevan. Analisis data dengan bivariat menggunakan uji chi square untuk mengetahui pengaruh kebermaknaan antara variabel dependen dan variabel independen.

\section{HASIL}

Karakteristik Umum Guru SMPN dan SMAN Yang Mengalami Gula Darah Puasa Terganggu

usia responden, untuk kelompok umur $\geq 50$ tahun lebih banyak sebesar $72,7 \%$ dibandingkan dengan kelompok umur $<50$ tahun yaitu 27,3\%. Berdasarkan tingkat pendidikan responden dapat dilihat bahwa 
lebih banyak pada tingkat sarjana yaitu 94,5\% dibandingkan dengan pascasarjana $5,5 \%$. Berdasarkan riwayat penyakit keluarga lebih banyak pada responden yang memiliki riwayat penyakit keluarga diabetes sebesar $74,5 \%$, dan yang paling sedikit adalah responden yang tidak memiliki riwayat penyakit keluarga yaitu $5,5 \%$. Berdasarkan lingkar perut, guru yang mengalami obesitas sentral lebih banyak sebesar $69,1 \%$ sedangkan yang tidak obesitas atau normal lebih sedikit sebesar $30,9 \%$.

Tabel 1. Distribusi Frekuensi Berdasarkan Karakteristik Guru SMPN dan SMAN Yang Mengalami Gula Darah Puasa Terganggu

\begin{tabular}{lcc}
\hline \multicolumn{1}{c}{ Variabel } & n & \% \\
\hline Jenis Kelamin & & \\
Laki-Laki & 10 & 18,2 \\
Perempuan & 45 & 81,8 \\
\hline Umur & & \\
$<50$ & 15 & 27,3 \\
$\geq 50$ & 40 & 72,7 \\
\hline Pendidikan & 52 & \\
Sarjana & 3 & 94,5 \\
Pasca Sarjana & & 5,5 \\
\hline Riwayat Penyakit Keluarga & 3 & 5,5 \\
Tidak Ada & 41 & 74,5 \\
Diabetes & 11 & 20 \\
Hipertensi & $\mathbf{5 5}$ & $\mathbf{1 0 0}$ \\
\hline Total & &
\end{tabular}

\section{Karakteristik Umum Guru SMPN dan SMAN Yang Mengalami Gula Darah Puasa Terganggu Dan Hipertensi}

Tabel 2 menunjukkan responden yang paling banyak mengalami hipertensi adalah laki-laki sebesar $100 \%$ dibandingkan dengan perempuan sebesar $82,2 \%$. Berdasarkan umur menunjukkan bahwa responden yang berumur $<50$ tahun lebih banyak mengalami hipertensi sebesar $86,7 \%$ dibandingkan dengan yang berumur $\geq 50$ tahun yaitu sebesar $85 \%$. Berdasarkan tingkat pendidikan, lebih banyak responden mengalami hipertensi dengan latar pendidikan pascasarjana yaitu $100 \%$ dibandingkan dengan responden yang tingkat pendidikan sarjana sebesar 84,6\%.

Berdasarkan riwayat penyakit keluarga, responden yang mengalami hipertensi lebih banyak pada responden yang memiliki riwayat keluarga hipertensi yaitu $90,9 \%$, kemudian yang memiliki riwayat diabetes $85,4 \%$, dan yang paling sedikit yang tidak memiliki riwayat keluarga $66,7 \%$. Berdasarkan lingkar yang mengalami hipertensi lebih banyak pada orang yang obesitas sentral sebesar $86,8 \%$ dibandingkan dengan yang normal atau tidak mengalami obesitas sentral sebesar 82,4\%. Hubungan Gaya Hidup (Pola Konsumsi, Perilaku Merokok,Tingkat Stres dan Aktivitas Fisik) Dengan Hipertensi

Berdasarkan tabel 3 dapat dilihat bahwa presentase guru pola konsumsi yang kurang lebih tinggi mengalami hipertensi yaitu sebesar 93,9\% dibandingkan dengan guru yang memiliki pola konsumsi yang cukup sebesar yaitu $72,7 \%$. Berdasarkan hasil uji chisquare menunjukkan bahwa ada hubungan yang signifikan antara pola konsumsi dengan kejadian hipertensi $(\mathrm{p}=0,049)$.

Persentase guru yang perokok lebih tinggi mengalami hipertensi sebesar $100 \%$ dibandingkan dengan yang bukan perokok sebesar 82,6\%. Menurut uji chisquare menunjukkan bahwa tidak ada hubungan 
yang signifikan antara perilaku merokok dengan hipertensi $(p=0,327)$.

Pada tingkat stres menunjukkan hipertensi lebih tinggi terjadi pada guru yang mengalami stres sebesar $100 \%$ dibandingkan dengan guru yang mengalami tidak mengalami stress (normal) sebesar 81,4\%. Hasil uji chisquare menunjukkan bahwa tidak ada hubungan yang signifikan antara tingkat stres dengan hipertensi $(p=0,178)$.
Berdasarkan aktivitas fisik menunjukkan presentase guru dengan aktivitas ringan lebih tinggi yaitu sebesar $88,6 \%$ dibandingkan dengan guru yang memiliki aktivitas sedang sebesar $72,7 \%$. Hasil uji analisis chisquare menunjukkan bahwa tidak ada hubungan yang signifikan antara aktivitas fisik dengan kejadian hipertensi $(p=0,335)$.

Tabel 2. Hubungan Karakterisik Responden Dengan Hipertensi Pada Guru SMPN dan SMAN Yang Mengalami Gula Darah Puasa Terganggu

\begin{tabular}{|c|c|c|c|c|c|c|}
\hline \multirow[t]{3}{*}{ Variabel } & \multicolumn{4}{|c|}{ Hipertensi } & \multicolumn{2}{|c|}{ Total } \\
\hline & \multicolumn{2}{|c|}{$\mathbf{Y a}$} & \multicolumn{2}{|c|}{ Tidak } & \multirow[b]{2}{*}{$\mathbf{n}$} & \multirow[b]{2}{*}{$\%$} \\
\hline & $\mathbf{n}$ & $\%$ & $\mathbf{n}$ & $\%$ & & \\
\hline \multicolumn{7}{|l|}{ Jenis Kelamin } \\
\hline Laki-Laki & 10 & 100 & 0 & 0,0 & 10 & 100 \\
\hline Perempuan & 37 & 82,2 & 8 & 17,8 & 45 & 100 \\
\hline \multicolumn{7}{|l|}{ Umur } \\
\hline$<50$ & 13 & 86,7 & 2 & 13,3 & 15 & 100 \\
\hline$\geq 50$ & 34 & 85 & 6 & 15 & 40 & 100 \\
\hline \multicolumn{7}{|l|}{ Pendidikan } \\
\hline Sarjana & 44 & 84,6 & 8 & 15,4 & 52 & 100 \\
\hline Pasca Sarjana & 3 & 100 & 0 & 0,0 & 3 & 100 \\
\hline \multicolumn{7}{|c|}{ Riwayat Penyakit Keluarga } \\
\hline Tidak Ada & 2 & 66,7 & 1 & 33,3 & 3 & 100 \\
\hline Diabetes & 35 & 85,4 & 6 & 14,6 & 41 & 100 \\
\hline Hipertensi & 10 & 90,9 & 1 & 9,1 & 11 & 100 \\
\hline
\end{tabular}

Sumber: Data Primer, 2017

Tabel 3. Hubungan Gaya Hidup (Status Merokok, Tingkat Stres, dan Aktivitas Fisik) Dengan Hipertensi Pada Guru SMPN dan SMAN Yang Mengalami Gula Darah Puasa Terganggu

\begin{tabular}{|c|c|c|c|c|c|}
\hline \multirow{3}{*}{ Variabel } & \multicolumn{4}{|c|}{ Hipertensi } & \multirow[t]{3}{*}{$\mathbf{p}$} \\
\hline & \multicolumn{2}{|c|}{ Ya } & \multicolumn{2}{|c|}{ Tidak } & \\
\hline & $\mathbf{n}$ & $\%$ & $\mathbf{n}$ & $\%$ & \\
\hline \multicolumn{6}{|l|}{ Pola Konsumsi (HEI 2010) } \\
\hline Kurang & 31 & 93,9 & 2 & 6,1 & 0,049 \\
\hline Cukup & 16 & 72,7 & 6 & 27,3 & \\
\hline \multicolumn{6}{|l|}{ Status Merokok } \\
\hline Perokok & 9 & 100 & 0 & 0,0 & $\mathbf{0 , 3 2 7}$ \\
\hline Bukan Perokok & 38 & 82,6 & 8 & 17,4 & \\
\hline \multicolumn{6}{|l|}{ Tingkat Stres } \\
\hline Stres & 12 & 100 & 0 & 0,0 & $\mathbf{0 , 1 7 8}$ \\
\hline Normal & 35 & 81,4 & 8 & 18,6 & \\
\hline \multicolumn{6}{|l|}{ Aktivitas Fisik } \\
\hline Ringan & 39 & 88,6 & 5 & 11,4 & $\mathbf{0 , 3 3 5}$ \\
\hline Sedang & 8 & 72,7 & 3 & 27,3 & \\
\hline
\end{tabular}

Sumber: Data Primer, 2017 


\section{PEMBAHASAN}

Penelitian ini menunjukkan bahwa terdapat hubungan antara pola konsumsi dengan hipertensi $(\mathrm{p}=0,049)$. Berbeda dengan perilaku merokok $(\mathrm{p}=0,327)$, tingkat stres $(0,178)$, dan aktivitas fisik (0,335), menunjukkan tidak memiliki hubungan bermakna secara statistik terhadap hipertensi. Meskipun tidak terdapat hubungan yang bermakna dari ketiganya namun jumlah responden yang perokok, mengalami stres, dan memiliki aktivitas ringan lebih tinggi mengalami hipertensi.

Dalam penelitian ini ditemukan bahwa konsumsi yang kurang akan lebih beresiko mengalami hipertensi. Pada penelitian ini responden sangat mengkonsumsi buah dan sayur padahal hal itu berpengaruh pada hipertensi. Hasil penelitian ini sejalan dengan penelitian di cina mengenai hubungan konsumsi buah dan kejadian penyakit kardiovaskular. Ternyata, konsumsi buah segar yang tinggi berhubungan dengan tingkat tekanan darah dan glukosa darah yang lebih rendah. Responden yang memakan buah segar setiap hari memiliki tekanan darah sistolik rendah $(4,0 \mathrm{mmHg})$ dan kadar glukosa darah (9,0 mg per desiliter) (Du, 2016). Penelitian serupa juga ada di jepang yang menyebutkan bahwa konsumsi buah-buahan, sayuran, potassium, dan vitamin $\mathrm{C}$ tingkat tinggi dikaitkan dengan risiko hipertensi yang jauh lebih rendah (Utsugi, et.al, 2008). Salah satu contoh buah yang baik untuk dikonsumsi adalah semangka. Buah ini memiliki khasiat untuk menurunkan tekanan darah karena mengandung citirulline dan arginine, zat ini mampu merangsang produksi senyawa kimia yang membantu pembuluh darah menjadi lentur dan rileks. Citrullineakan bereaksi dengan enzim tubuhdan diubah menjadi arginine, sejenis asam amino yang berkhasiat bagi jantung dan sistem peredaran darah dan kekebalan tubuh yang terbukti menurunkan tekanan darah penderita hipertensi. Seperti pada penelitian pemberian jus semangka pada penderita hipertensi dapat menurunkan tekanan darah penderita hipertensi dengan obesitas 10-20 mmHg pada siastolik maupun diastolik (Shanti, 2016).

Sebaliknya dengan makanan lain, jenis makanan yang tidak boleh berlebih atau sering dikaitakan dengan hipertensi adalah natrium (garam). Menurut hasil penelitian, konsumsi natrium yang berlebih berhubungan dengan terjadinya hipertensi. Hal ini didukung dengan penelitian lain yang menunjukkan bahwa mengkonsumsi natrium dalam jumlah yang tinggi 5,6 kali lebih besar terkena hipertensi dibandingkan dengan yang mengkonsumsi natrium dalam jumlah yang rendah. Natrium, jika dikonsumsi lebih banyak akan meretensi lebih banyak air untuk mempertahankan pengenceran elektrolit, sehingga cairan intestin bisa terakumulasi dan volume plasma meningkat (Mulyati, et al, 2011).

Berbeda halnya dengan perilaku merokok, pada penelitian ini menunjukkan bahwa tidak ada hubungan yang signifikan.Pada penelitian ini, responden yang tidak merokok lebih banyak dibandingkan dengan responden yang merokok. Hal ini disebabkan karena mayoritas responden yang diteliti adalah perempuan. Hasil penelitian ini cukup berlawanan dengan penelitian yang dilakukan di kota Padang mengenai hubungan merokok dengan kejadian hipertensi pada laki-laki usia 35-65 tahun bahwa ada hubungan antara kebiasaan merokok dengan hipertensi $(p=0,003)$ yaitu dipengaruhi oleh lama merokok $(\mathrm{p}=0,017)$ dan jenis rokok $(\mathrm{p}=0,017)$ (Setyanda, 2015). Didukung dengan penelitian bahwa tekanan darah tinggi sistolik dan diastolik lebih sering terjadi pada perokok dibandingkan dengan nonperokok (Ain, 2015).Hipertensi dapat disebabkan oleh perilaku merokok dapat hal ini dikarenakan zat-zat kimia yang terkandung di dalam tembakau yang mampu dengan mudah merusak lapisan dalam dinding arteri, sehingga arteri lebih rentan terjadi penumpukan plak (arterosklerosis). Selain itu nikotin yang 


terkandung dalam rokok dapat
menyebabkan ransangan yang cepat kepada saraf simpatis sehingga memacu kerja jantung lebih keras dan menyebabkan penyempitan pembuluh darah, kemudian adanya peran serta karbonmonoksida yang dapat menggantikan oksigen dalam darah dan memaksa jantung memenuhi kebutuhan oksigen tubuh.

Tingkat stresjuga menunjukkan tidak ada hubungan terhadap hipertensi $(\mathrm{p}=0,178)$ hal ini tidak sejalan dengan penelitian di Cina, pada kelompok umur 40-60 dimana stres secara signifikan berhubungan dengan hipertensi. Stres berkontribusi sekitar 9,1\% terhadap risiko hipertensi ( $\mathrm{Hu}$, et. al, 2015). Kondisi stres meningkatkan aktivitas saraf simpatis yang kemudian meningkatkan tekanan darah secara bertahap, artinya semakin berat kondisi stres seseorang maka semakin tinggi pula tekanan darahnya. Jika seseorang merasa tertekan atau stress, hal inilah membuat tubuh menghasilkan hormon adrenalin lebih banyak, yang menyebabkan jantung berkerja lebih kuat dan cepat tidak seperti dalam keadaan normal.kondisi stres dialami penderita hipertensi maka akan mempengaruhi peningkatan tekanan darahnya, yang cenderung akan menetap atau bahkan dapat bertambah tinggi sehingga menyebabkan kondisi hipertensinya menjadi lebih berat (Lawson, 2007).

Berdasarkan aktivitas fisik menunjukkan presentase guru dengan aktivitas ringan lebih tinggi yaitu sebesar $88,6 \%$ dibandingkan dengan guru yang memiliki aktivitas sedang sebesar $72,7 \%$. Hasil uji analisis chisquare menunjukkan bahwa tidak ada hubungan yang signifikan antara status merokok dengan kejadian hipertensi $(\mathrm{p}=0,335)$. Hasil penelitian serupa pada laki-laki yang berusia 40 tahun keatas yang tinggal di Kelurahan Bahoi provinsi Sulawesi Utara tidak terdapat hubungan antara aktivitas fisik $\quad(p=0,752) \quad$ (Kudati, 2016). Sebenarnya, aktivitas yang rendah akan menurunkan elastisitas sistem jantung dan pembuluh darah begitupun sebaliknya, aktivitas yang tinggi akan meningkatkan elastisitas sistem jantung dan pembuluh darah, karena setelah beraktivitas, tekanan darah arteri akan meningkat (WHO, 2013). Hasil ini diperkuat oleh penelitian di Sudan bahwa memiliki aktivitas fisik yang rendah mengakibatkan risiko lebih tinggi terjadi hipertensi dibandingkan dengan aktivitas fisik yang tinggi, jika seseorang tidak aktif dalam beraktivitas maka memiliki risiko 30-50\% lebih besar menderita hipertensi daripada mereka yang lebih aktif secara fisik (Elhuda, 2014). Tekanan darah akan meningkat ketika sedang melakukan aktivitas fisik. Akan tetapi, jika seseorang melakukan aktivitas fisik secara teratur maka akan jauh lebih sehat dan baik, karena tekanan darahnya akan lebih rendah daripada seseorang yang tidak melakukan aktivitas fisik (Beavers, 2002). Aktivitas fisik yang cukup dapat membantu menguatkan jantung. Semakin ringan kerja jantung, maka semakin sedikit tekanan pada pembuluh darah arteri sehingga mengakibatkan tekanan darah menjadi turun. Beberapa studi juga menunjukkan bahwa olahraga yang dilakukan secara rutin dan teratur dapat mengurangi faktor risiko terhadap penyakit jantung koroner, termasuk hipertensi (Simamora, 2012).hal ini juga didukung oleh pemerintah melalui Kementrian Kesehatan RI dalam gerakan masyarakat hidup sehat (GERMAS) dalam mewujudkan Indonesia sehat salah pesannya adalah melakukan aktivitas fisik selama 30 menit dalam sehari.

\section{KESIMPULAN DAN SARAN}

Pola konsumsi memiliki hubungan dengan hipertensi, akan tetapi perilaku merokok, tingkat stress, dan ativitas fisik tidak terdapat hubungan antara dengan hipertensi guru SMPN dan SMPN yang mengalami gula darah puasa terganggu. Kepada responden diharapkan untuk meningkatkan makanan yang bergizi dan seimbang terutama buah dan sayur, mengontrol konsumsi garam dan makanan berlemak untuk terhindar dari penyakit 
degeneratif. Selain itu, menghindari perilaku merokok, selalu berpikir dan bertindak positif, aktif melakukan aktivitas fisik minimal 30 menit per hari.Diperlukan upaya mengalakkan program pendidikan kesehatan di lingkungan sekolah mengenai gaya hidup sehat. Diperlukan peran pemerintah menyediakan akses pelayanan kesehatan berupa surveilans di tingkat sekolah dengan melakukan pemeriksaan darah secara berkala pada guru-guru agar mengetahui secara jelas kondisi kesehatannya.

\section{DAFTAR PUSTAKA}

Ain, Qurrat ul, Regmi, Krishna. (2015).The Effects Of Smoking In Developing Hypertension In Pakistan: A Systematic Review. South East Asia Journal of Public Health. 2015;5(1):4-11

A.M, Bhende, et.al. (2012). Influence Of Family Hypertension On Blood Pressure, SerumCholesterol, High Density Lipoprotein Cholesterol In GeneralPopulation. International Journalof Pharma And Bio Sciences. Vol 3/Issue 1/JanMar 2012

Andriansyah, Hengky. (2014). Analisis Hubungan Faktor - Faktor Risiko Hipertensi Dengan Kejadian Hipertensi Pada Penduduk Usia 20-65 Tahun Di Kecamatan Kaliwates Kabupaten Jember.(Tesis). Jember. Universitas Jember

Beavers, D. G. (2002). Tekanan darah, Jakarta: Dian Rakyat.

Bustan M.N. (2007). Epidemiologi Penyakit Tidak Menular. Edisi Kedua. Jakarta: Rineka Cipta

Dalimartha. S. (2008). Care Your Self Hipertensi. Jakarta : Penebar Plus

Dinas Kesehatan Provinsi Sulawesi Selatan. (2015). Profil Kesehatan Provinsi Sulawesi

Selatan2014. Dinas Kesehatan

Provinsi Sulawesi Selatan, Makassar
Du, Huaidong, et. al. (2016). Fresh Fruit Consumption and Major Cardiovascular Disease in China. $N$ Engl J Med 2016; 374:1332-1343. DOI: 10.1056/NEJMoa1501451

Elhuda, Daffalla A'lam. (2014). Hypertension Among Women In Tiraira Madani, RuralSudan: Prevalence And Risk Factors. www.advancejournals.orgInternati onal Journal of Medicine \& HealthResearch, 2(2).1-10ESC Guidelines. (2013). ESC Guidelines on diabetes, prediabetes, andcardiovascular diseases developed in collaboration with the EASD.European Heart Journal, 34, 3035-3087

$\mathrm{Hu}$ B, et. al. (2015). Effects of Psychological Stress on Hypertension in Middle-Aged Chinese: A Cross-Sectional Study. PLoS ONE 10(6): e0129163. https://doi.org/10.1371/journal.pon e. 0129163

International Diabetes Federation. (2015).IDF diabetes atlas 2015. 7th ed.

Brussels: International Diabetes Federation

Kaplan, N. (2002). Hypertension In The Elderly Second Edition. London: Martin Dunitz Ltd).

Kementerian Kesehatan. 2013. Badan Penelitian dan Pengembangan Kesehatan. Laporan Nasional: Riset Kesehatan Dasar (Riskesdas)2013. Jakarta: Balitbangkes Kemenkes RI

Kudati, Indra Galia., dkk. (2017).FaktorFaktor Yang Berhubungan Dengan Kejadian Hipertensi Pada LakiLaki Yang Berusia 40 Tahun Ke Atas Di Kelurahan Bahoi Kecamatan Tagulandang Kabupaten Siau Tagulandang Biaro. Fakultas Kesehatan Masyarakat Universitas Sam Ratulangi. Jurnal Ikmas. Vol 1, No 7 (2017): Vol 1, No 7 
Lawson, RW, et.al. (2007). Systemic Hypertension:Mechanisms and Diagnosis.

Philadelphia: Saunders Elsevier

Lipoeto NI. (2002). Kejadian Hipertensi dan Beberapa Faktor Risikonya di Padang. (Skripsi). Padang. Universitas Andalas

Malekzadeh, Masoud M. et. al. (2012). Prevalence, awareness and risk factors of hypertension in a large cohort of Iranian adult population. Journal of Hypertension, Hypertens31:000000,DOI:10.1097/ HJH.0b013e3283613053, www.jhypertension.com

Mulyati, H., A. Syam., dan S. Sirajuddin. (2011). Hubungan Pola Konsumsi Natrium dan Kalium serta Aktivitas Fisik dengan Kejadian Hipertensi pada Pasien Rawat Jalan di RSUP Dr. Wahidin Sudirohusodo Makassar.

Media Gizi Masyarakat Indonesia. Vol.1, No. 1. Hal: 46-51

National Institutes of Health, National Heart, Lung, and Blood Institute, National High Blood $\backslash$ Pressure Education Program. (2004). The Seventh Report of The Joint National

Committee on Prevention.

Detection, Evaluation and

Treatment of High Blood

Pressure. NIH Publication No. 045230

Perkeni. (2015). Konsensus Pengelolaan Dan Pencegahan DM Tipe 2 Di Indonesia. Penerbit PB. Perkeni

Qin Yu, Melse-Boonstra \& Pan, X., (2014). Association of dietary pattern and body weight with blood pressure in Jiangsu Province, China. BMC public health.14, p.948.

Setyanda,Yashinta., dkk. (2015). Hubungan Merokok dengan Kejadian Hipertensi pada LakiLaki Usia 35-65 Tahun di Kota Padang. Jurnal Kesehatan Andalas.
2015;

http://jurnal.fk.unand.ac.id

Shanti, Ni Made, Zuraida, Reni. (2016). Pengaruh Pemberian Jus Semangka TerhadapPenurunan Tekanan Darah Lansia. MajorityI. Volume 5 I Nomor 4 I Oktober 2016.

Simamora, J. P. (2012). Pengaruh Karakteristik dan Gaya Hidup Kelompok Dewasa Madya Terhadap Kejadian Hipertensi Di Wilayah Kerja Puskesmas Matiti Kabupaten Humbang Hasundutan. (Tesis). Sumatera. Universitas Sumatera

Utara.,http://repository.usu.ac.id/ha ndle/123456789/35690

Sitorus, Ronald H. (2005). Gejala Penyakit dan Pencegahannya. Bandung: Yrama Wiidya

Tadvi Amrin Y, Bandi Janardhan R. (2016). An epidemiological crosssectional study to assess the level of stress and its association with hypertension in young adult population of age group 20 to 40 years in an urban slum of Mumbai, Maharashtra, India. International Journal of Community Medicine and Public Health. pISSN 2394-

6032. http://www.ijcmph.com

Tee, Syer Ree, et. al. (2010). The Prevalence Of Hypertension And Its Associated Risk Factors In Two Rural Communities In Penang, Malaysia. IeJSME 2010: 4(2): 2740. Department of Public Health Medicine, Penang Medical College Utsugi, Megumi T, et. al. (2008). Fruit and Vegetable Consumption and the Risk of

Hypertension Determined by Self Measurement of Blood Pressure at Home: The Ohasama Study. Hypertension Research (2008) 31, 1435-1443; doi:10.1291/hypres.31.1435

WHO. (2013). A Global Brief On Hypertasion. Geneva: World Health Organization. http://ish- 